\title{
Experimental Study of Functionally Graded Beam with Fly Ash
}

\author{
K. Bajaj · Y. Shrivastava $\cdot$ P. Dhoke
}

Received: 20 November 2013/ Accepted: 26 March 2014/Published online: 1 May 2014

(C) The Author(s) 2014. This article is published with open access at Springerlink.com

\begin{abstract}
Generally, concrete used in the field suffers from lack of durability and homogeneity. As cement is the only binding material in concrete and due to hike in its price, researchers have been looking for apt substitutes. For the sake of economy, strength and anti-corrosion functionally graded beam (FGB) has developed having one layer of normal concrete and another of high volume flyash concrete (HVFAC). The flexural behavior FGB has analyzed experimentally in this work with variation in interface as $0,25,50,75$ and 100 from bottom. In this study, HVFAC has prepared with replacement of cement by 20,35 and $55 \%$ with fly ash for M20 and M30 grade of concrete. It has seemed that there is 12.86 and $3.56 \%$ increase in compressive and flexural strength of FGB. The bond strength FGM cube is optimum at $50 \mathrm{~mm}$ depth. As FGM is economical, having more durability and strength, so its adoption enables more sustainability in concrete industry.
\end{abstract}

Keywords Functionally graded material . Compressive strength · Bond strength · Fly ash . Flexural strength

Y. Shrivastava $\cdot$ P. Dhoke

University of Petroleum and Energy Studies, Dehradun 248006,

Uttarakhand, India

K. Bajaj $(\bowtie)$

Applied Mechanics Department, Sardar Vallabhbhai National

Institute of Technology, Surat, India

e-mail: 16ketan1990@gmail.com

\section{Introduction}

Advance in material amalgamation technologies have invigorated the development of a new class of materials, called functionally graded materials (FGM), with promising applications in aerospace, infrastructure, energy [1], electronics and biomedical engineering [2]. FGM comprises of a multi-phase material with different fractions of the constituents varying gradually in a pre-determined (designed) profile, thus yielding an inhomogeneous microstructure having continuously graded properties.

Static and dynamic analyses of FGM structures have attracted various researchers in the last few decades. The researchers have proposed an elastic solution based on Euler-Bernoulli beam theory for functionally graded beam (FGB) subjected to static transverse loads by supposing Young's modulus of the beam differs exponentially through the thickness [3]. Similarly a new finite element beam based on the first-order shear deformation theory had suggested by various literatures [4] to study the thermoelastic behavior of FGM structure. The researchers have presented an analytical solution to cantilever beam which is based on two dimension elastic theory with indiscriminate graded variation of material distribution [5]. Using third order zigzag theory for estimating effective modulus of elasticity, the scientists have studied [6] a finite element model for static and free vibration responses of layered FGB. The researchers have studied the static behavior of FGB and proposed an analytical solution to bending problem of a synthetic FGB [7, 8]. In these theories neutral surface is coincide with the geometric mid-surface. But, because of variation in the material properties, neutral surface of the FGB may not coincide and varies with thickness or position of interface. In the present work, interface has been varied from $0,25,50,75$ and $100 \mathrm{~mm}$ 
Fig. 1 Variation of stress in FGM

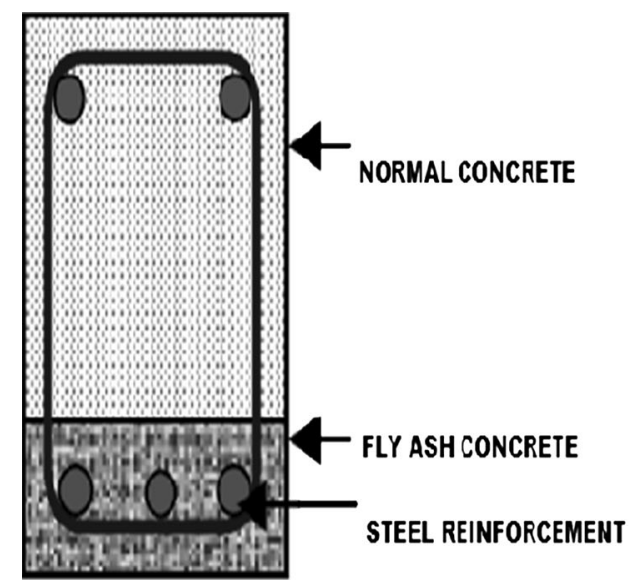

and the effect on compressive strength and flexural strength has been studied experimentally and evaluated analytically.

Fly ash is a by-product of crushed coal, is widely used as a cementitious and Pozzolanic ingredient in Hydraulic cement concrete. According to ACI 116R (American Concrete Institute) fly ash is [9] "The finely divided residue that results from the combustion of ground or powdered coal and is transported by flue gases from a combustion zone to a particle removal system".

The cementitious property of fly ash is due to its reactive constituents that reside within fly ash, such as calcium, silicate and aluminates. Fly-Ash enhances the workability, compressive strength, flexural strength, pumpability, durability and concrete finishing. So its use in designing of FGM makes it more economical as compared to normal concrete or fly ash concrete.

Structural Engineering Research Institute [10] reported that HVFAC exhibited higher strength at later ages and the flexural strength is higher for HVFAC whereas the bond strength for embedded rebar is nearly the same for both the concretes but it shows very low chloride permeability and low water absorption and reduced water permeability and have lower carbonation depth however better abrasion resistance as compared to that of OPC based concrete which increases the age of the concrete. Also finalized that the crack widths under service load for both OPC and HVFAC beam specimens are within the permissible limit as per provisions of IS:456-2000 and the ultimate load carrying capacity of both the reinforced OPC based concrete and HVFAC based columns under axial compression is nearly the same. The concept of functionally graded concrete (FGC) beam is to improve durability over regular reinforced concrete structures has been proposed by various researchers [11]. In this study ultrahigh toughness cementitious composite was used as a replacement for the concrete material that surrounds the main reinforcement in a reinforced concrete structural member. Later many investigations were carried out to realize the full potential of FGM in the field of construction. The literatures have shown that increased early strengths can be achieved in fly ash concrete by using high-range water-reducing admixtures and reducing the w/c to at least as low as 0.28 and changes in the cement source can change the strengths of concrete with Class-F fly ash as much as $20 \%$ [12].

Functionally graded material beam as shown in Fig. 1 with normal concrete and fly ash has the great resistance against corrosion, thermal cracking and have excellent

Table 1 Chemical property of fly ash and cement used

\begin{tabular}{|c|c|c|}
\hline Properties & FA & Cement \\
\hline \multicolumn{3}{|l|}{ Chemical properties } \\
\hline $\mathrm{SiO}_{2}$ & 53.36 & 21.2 \\
\hline $\mathrm{Al}_{2} \mathrm{O}_{3}$ & 29.46 & 6.25 \\
\hline $\mathrm{Fe}_{2} \mathrm{O}_{3}$ & 10.86 & 2.5 \\
\hline $\mathrm{CaO}$ & 2.42 & 64.3 \\
\hline \multicolumn{3}{|l|}{ Physical properties } \\
\hline Fineness, $\mathrm{m}^{2} / \mathrm{kg}$ & 325 & 390 \\
\hline Loss of ignition, $\%$ & 1.0 & 5.0 \\
\hline Specific gravity & 3.15 & 2.65 \\
\hline
\end{tabular}

Table 2 Physical properties of fly ash used

\begin{tabular}{ll}
\hline Physical properties & Value \\
\hline Liquid limit & $23.9 \%$ \\
Plastic limit & $13.14 \%$ \\
Plastic index & $10.76 \%$ \\
Specific gravity & 2.65 \\
Optimum moisture content & $31.2 \%$ \\
Maximum dry density & $1.2 \mathrm{~g} / \mathrm{cc}$ \\
Cohesion & Negligible \\
Angle of internal friction & $35^{\circ}$ \\
Permeability & $1.3 \times 10^{-4} \mathrm{~cm} / \mathrm{s}$ \\
\hline
\end{tabular}


Table 3 Physical properties of aggregate

\begin{tabular}{|c|c|c|}
\hline Properties & Fine aggregate & Coarse aggregate \\
\hline Impact value & - & 9.76 \\
\hline Crushing value & - & 28.95 \\
\hline Bulk density, $\mathrm{g} / \mathrm{cm}^{3}$ & 1.948 & 1.635 \\
\hline Specific gravity & 2.62 & 2.60 \\
\hline Fineness modulus & 2.71 & 2.67 \\
\hline
\end{tabular}

compressive strength. As the concrete is weak in its tensile strength, so it is economical to use FGB. FGM beam is designed with M20 and M30 grade above the interface and below with the HVFAC having 20, 35 and $55 \%$ replacement of cement with fly ash. It seems as the Bamboo structure having resistance against compression and deflection. The weakness of concrete such as shrinkage during coagulation and hardening, low tensile strength, poor crack resistance, brittleness, small ultimate extension and bad impact endurance, which prevails in concrete and limits its application, has been thoroughly dealt with in FGM.

\section{Experimental Investigation}

\section{Properties of Material Used}

Fly Ash and Cement

The fly ash (FA) has been used in the experimentation is of ASTM Class-F and taken from Chunna Bhatta of Dehradun, Uttrakhand, India. The following are the physical and chemical properties of the fly ash $[13,14]$ that are shown in Tables 1 and 2:-

\section{Coarse and Fine Aggregate}

The properties of fine and coarse aggregate [15-17] used in the experiment are shown in Table 3.

\section{Methodology Adopted}

In this investigation, the compressive strength of FGM cubes was determined at an interval of $7,28 \& 56$ days

Table 4 Detail of normal cube with fly ash

\begin{tabular}{lllll}
\hline M20 & & & M30 & \\
\cline { 1 - 2 } Mix identification & Concrete mix proportion & & Mix identification & Concrete mix proportion \\
\hline M21 & M20 concrete with $100 \%$ cement $+0 \%$ fly ash & M31 & M30 concrete with $100 \%$ cement $+0 \%$ fly ash \\
M22 & M20 concrete with $80 \%$ cement $+20 \%$ fly ash & & M32 & M30 concrete with $80 \%$ cement $+20 \%$ fly ash \\
M23 & M20 concrete with $65 \%$ cement $+35 \%$ fly ash & & M33 & M30 concrete with $65 \%$ cement $+35 \%$ fly ash \\
M24 & M20 concrete with $45 \%$ cement $+55 \%$ fly ash & & M34 & M30 concrete with $45 \%$ cement $+55 \%$ fly ash \\
\hline
\end{tabular}

Table 5 Detail of FGM cubes

\begin{tabular}{|c|c|c|c|c|c|c|c|}
\hline \multicolumn{4}{|l|}{ M20 } & \multicolumn{4}{|l|}{ M30 } \\
\hline \multirow[t]{2}{*}{$\begin{array}{l}\text { Cubes } \\
\text { mix }\end{array}$} & \multicolumn{3}{|c|}{ Concrete mix proportion } & \multirow[t]{2}{*}{$\begin{array}{l}\text { Cubes } \\
\text { mix }\end{array}$} & \multicolumn{3}{|c|}{ Concrete mix proportion } \\
\hline & \multicolumn{6}{|c|}{ For M23 and M33 cubes } & \\
\hline \multirow[t]{2}{*}{ M22F } & M22FL & M22FM & $\mathrm{M} 22 \mathrm{FU}$ & $\mathrm{M} 32 \mathrm{~F}$ & M32FL & M32FM & M32FU \\
\hline & $\begin{array}{l}\text { M21 } \\
\quad(125 \mathrm{~mm})+\mathrm{M} 22 \\
\quad(25 \mathrm{~mm})\end{array}$ & $\begin{array}{l}\text { M21 } \\
\quad(75 \mathrm{~mm})+\text { M22 } \\
\quad(75 \mathrm{~mm})\end{array}$ & $\begin{array}{l}\text { M21 } \\
\quad(25 \mathrm{~mm})+\text { M22 } \\
(175 \mathrm{~mm})\end{array}$ & & $\begin{array}{l}\text { M31 } \\
\quad(125 \mathrm{~mm})+\mathrm{M} 32 \\
\quad(25 \mathrm{~mm})\end{array}$ & $\begin{array}{l}\text { M31 } \\
\quad(75 \mathrm{~mm})+\text { M32 } \\
\quad(75 \mathrm{~mm})\end{array}$ & $\begin{array}{l}\text { M31 } \\
\quad(25 \mathrm{~mm})+\text { M32 } \\
(175 \mathrm{~mm})\end{array}$ \\
\hline \multicolumn{8}{|c|}{ For M23 and M33 cubes } \\
\hline \multirow[t]{2}{*}{$\mathrm{M} 23 \mathrm{~F}$} & M23FL & M23FM & $\mathrm{M} 23 \mathrm{FU}$ & M33F & M33FL & M33FM & M33FU \\
\hline & $\begin{array}{l}\text { M21 } \\
\quad(125 \mathrm{~mm})+\mathrm{M} 23 \\
\quad(25 \mathrm{~mm})\end{array}$ & $\begin{array}{l}\text { M21 } \\
\quad(75 \mathrm{~mm})+\mathrm{M} 23 \\
\quad(75 \mathrm{~mm})\end{array}$ & $\begin{array}{l}\text { M21 } \\
\quad(25 \mathrm{~mm})+\mathrm{M} 23 \\
\quad(175 \mathrm{~mm})\end{array}$ & & $\begin{array}{l}\text { M31 } \\
\quad(125 \mathrm{~mm})+\mathrm{M} 33 \\
\quad(25 \mathrm{~mm})\end{array}$ & $\begin{array}{l}\text { M31 } \\
\quad(75 \mathrm{~mm})+\mathrm{M} 33 \\
\quad(75 \mathrm{~mm})\end{array}$ & $\begin{array}{l}\text { M31 } \\
\quad(25 \mathrm{~mm})+\mathrm{M} 33 \\
\quad(175 \mathrm{~mm})\end{array}$ \\
\hline \multicolumn{8}{|c|}{ For M23 and M33 cubes } \\
\hline \multirow[t]{2}{*}{$\mathrm{M} 24 \mathrm{~F}$} & M24FL & M24FM & M24FU & M34F & M34FL & M34FM & M34FU \\
\hline & $\begin{array}{l}\text { M21 } \\
\quad(125 \mathrm{~mm})+\mathrm{M} 24 \\
\quad(25 \mathrm{~mm})\end{array}$ & $\begin{array}{l}\text { M21 } \\
\quad(75 \mathrm{~mm})+\text { M24 } \\
\quad(75 \mathrm{~mm})\end{array}$ & $\begin{array}{l}\text { M21 } \\
\quad(25 \mathrm{~mm})+\mathrm{M} 24 \\
\quad(175 \mathrm{~mm})\end{array}$ & & $\begin{array}{l}\text { M31 } \\
\quad(125 \mathrm{~mm})+\text { M34 } \\
\quad(25 \mathrm{~mm})\end{array}$ & $\begin{array}{l}\text { M31 } \\
\quad(75 \mathrm{~mm})+\text { M34 } \\
\quad(75 \mathrm{~mm})\end{array}$ & $\begin{array}{l}\text { M31 } \\
\quad(25 \mathrm{~mm})+\text { M34 } \\
\quad(175 \mathrm{~mm})\end{array}$ \\
\hline
\end{tabular}


(a)

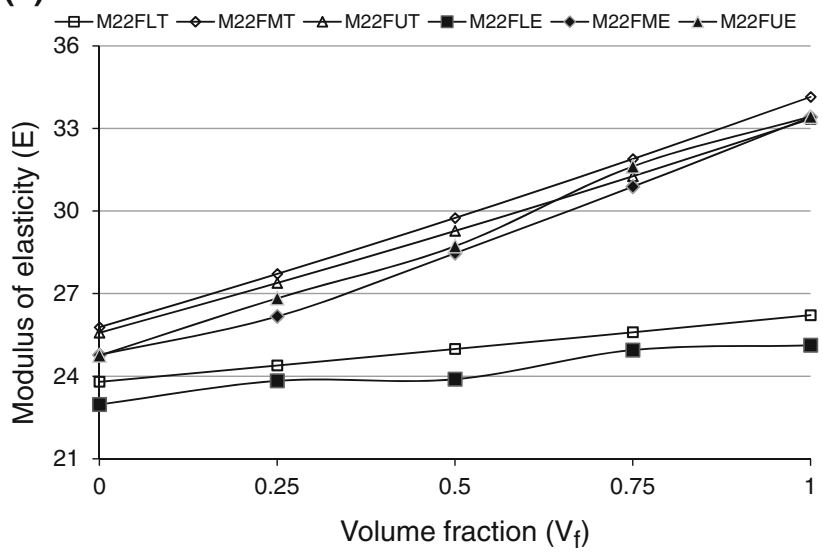

(c)

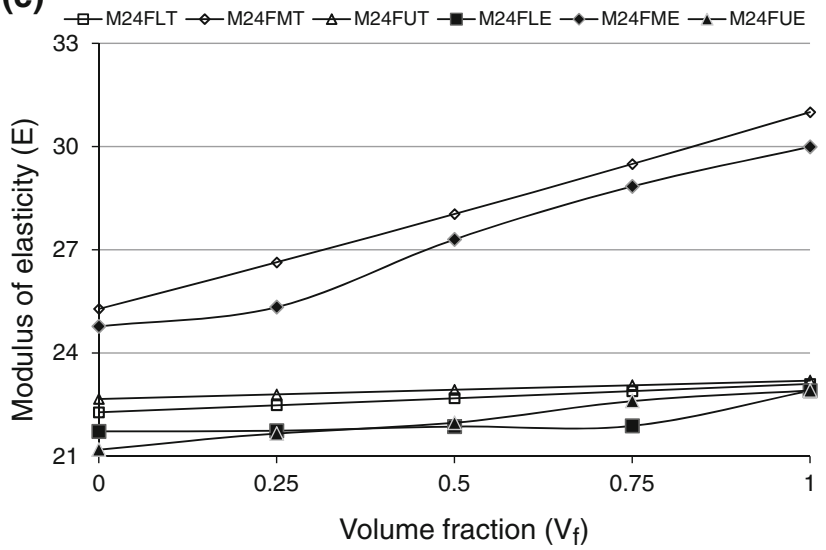

(e)

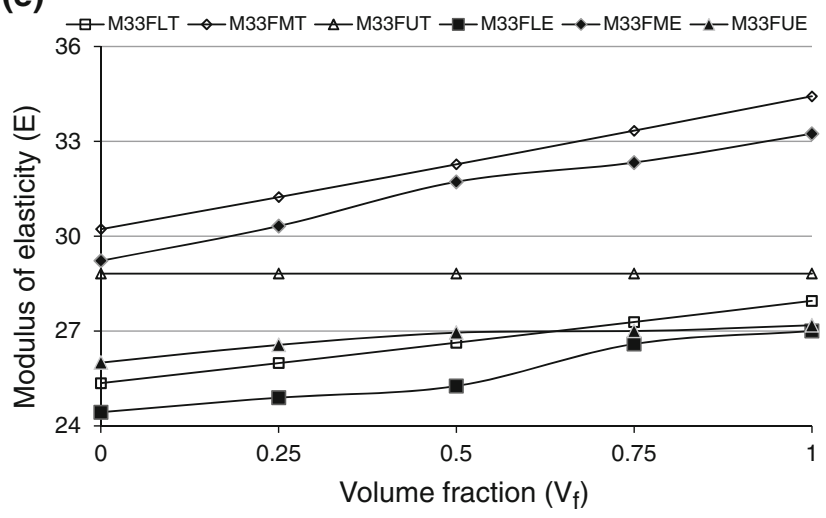

Fig. 2 The variation of Young's Modulus with volume fraction of different grade of concrete where ' $T$ ' represents theoretical and ' $E$ ' represents experimental. a Variation of Young's Modulus with Volume fraction of M22 Grade. b Variation of Young's Modulus with Volume fraction of M23 Grade. c Variation of Young's Modulus with

with the replacement of cement @ $(20,35$ and $55 \%)$ with fly ash with changing an interface as 25,75 and $125 \mathrm{~mm}$. Besides this flexural strength of $600 \times 150 \times 100 \mathrm{~mm}^{3}$ prism of M20 and M30 Grade with above replacement of cement with FA had tested with variation in interface as 25 , (b)

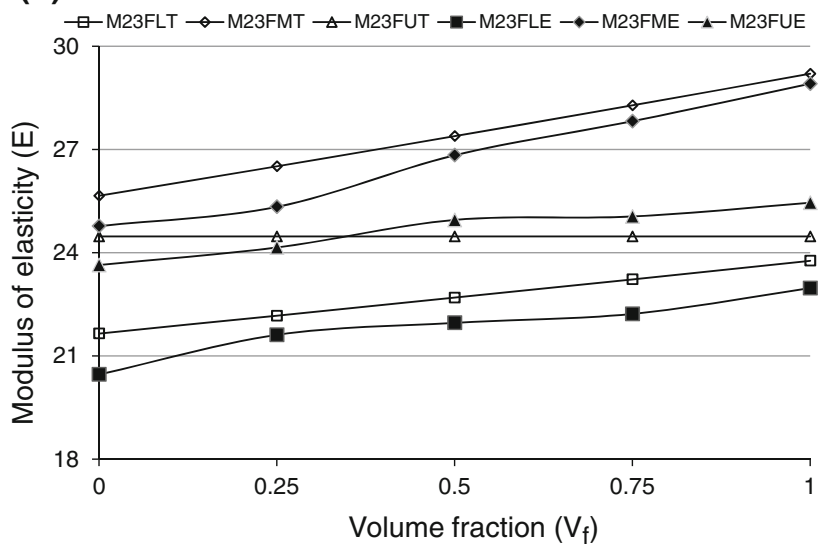

(d)

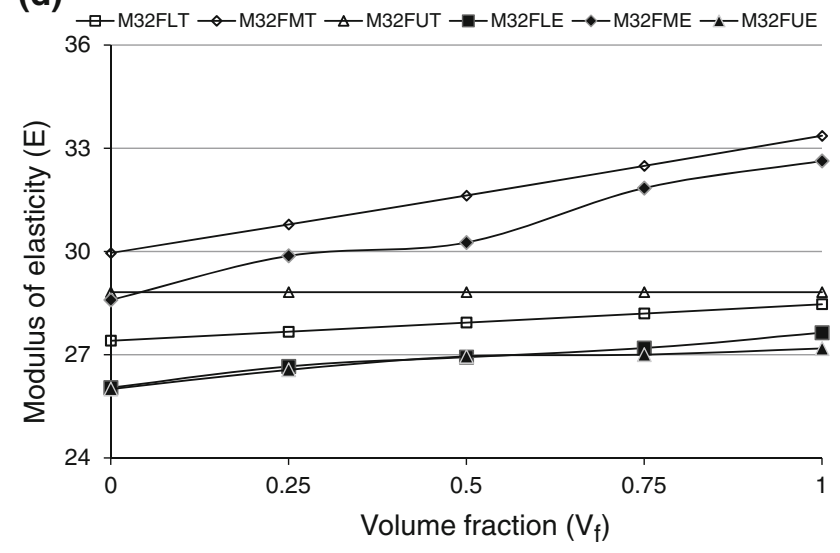

(f)

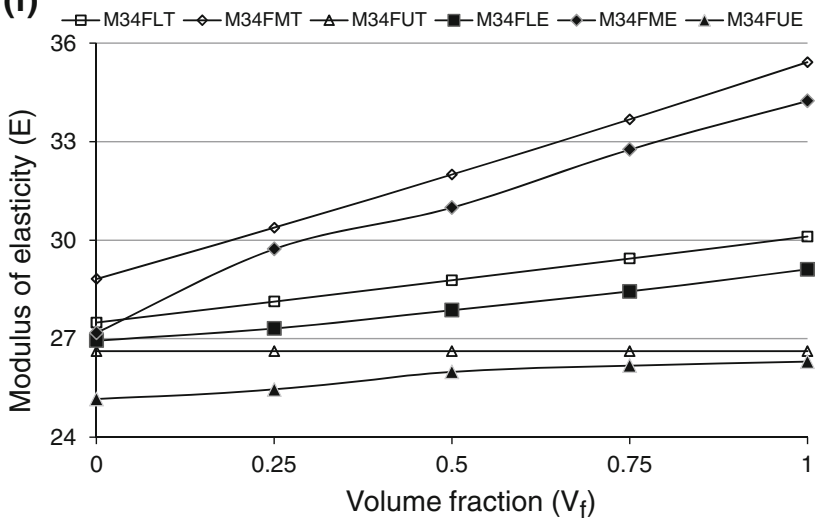

Volume fraction of M24 Grade. d Variation of Young's Modulus with Volume fraction of M24 Grade. e Variation of Young's Modulus with Volume fraction of M24 Grade. f Variation of Young's Modulus with Volume fraction of M34 Grade

50 and $100 \mathrm{~mm}$. The bond strength with concrete cube is also tested at interface. The compressive strength and flexural strength of normal concrete, fly ash concrete, high volume fly ash concrete and functionally graded material concrete is compared. 
(a)

$$
\rightarrow \mathrm{M} 21 \rightarrow \mathrm{M} 22 \rightarrow \mathrm{M} 22 \mathrm{FL} \rightarrow \mathrm{M} 22 \mathrm{FM} \rightarrow \mathrm{M} 22 \mathrm{FU}
$$

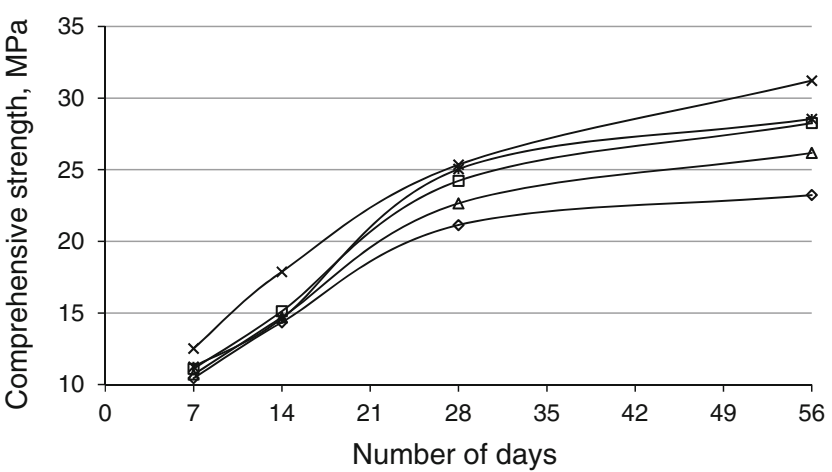

(c)

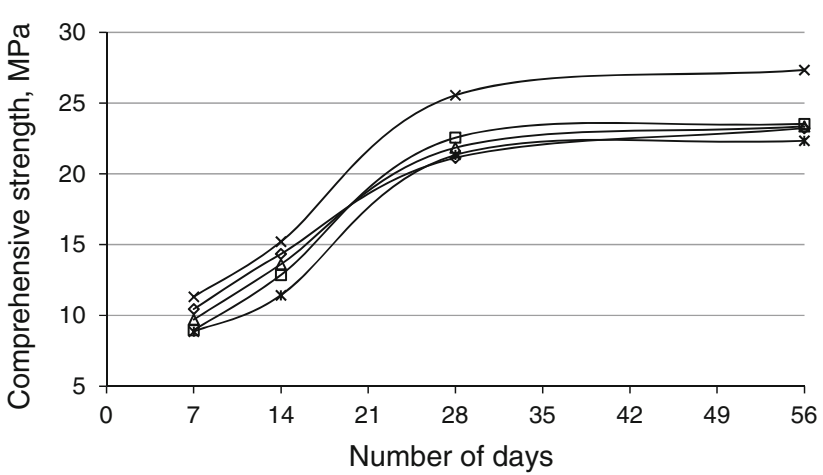

(e) $\rightarrow-\mathrm{M} 31 \rightarrow-\mathrm{M} 33 \rightarrow-\mathrm{M} 33 \mathrm{FL} \rightarrow \mathrm{M} 33 \mathrm{FM} \rightarrow \mathrm{M} 33 \mathrm{FU}$

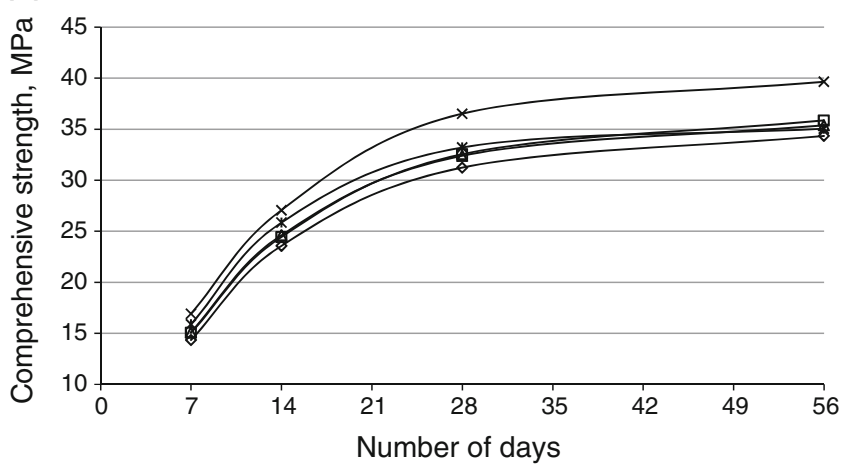

Fig. 3 The compresive strength of different cubes as per Tables 4 and 5. a Compressive strength of M22 cubes with FGM. b Compressive strength of M23 cubes with FGM. c Compressive strength of

\section{Mixing and Sampling}

One control mixture M1 (without fly ash) was designed as per standard specification IS 10262:1982 for the mix design of M20 and M30 with target mean strength of $26.25 \mathrm{MPa}$, $36.69 \mathrm{MPa}$ [18]. The other three concrete mix were designed with 20,35 and $55 \%$ replacement of cement with fly ash is made of M20 and M30 grade of concrete with variation in interface. The compressive strength [19] was determined by $150 \times 150 \times 150 \mathrm{~mm}^{3}$ mould and flexural (b)

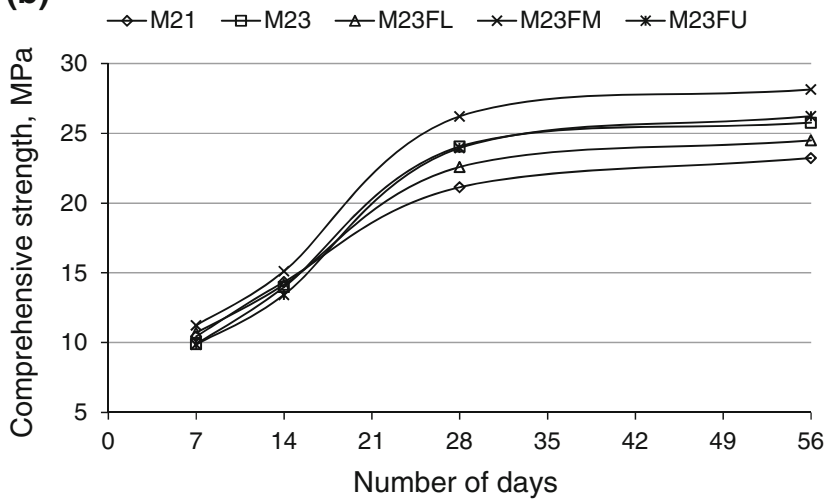

(d)
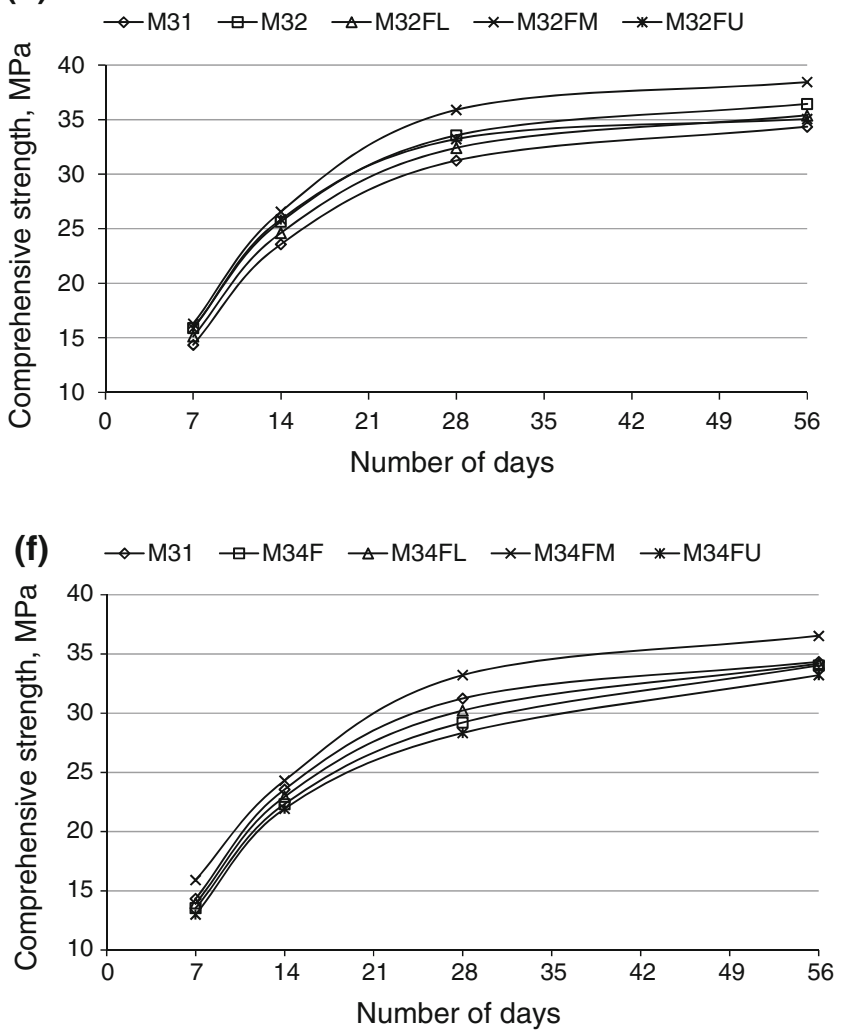

M24 cubes with FGM. d Compressive strength of M32 cubes with FGM. e Compressive strength of M33 cubes with FGM. f Compressive strength of M34 cubes with FGM

strength [19] by $600 \times 150 \times 100 \mathrm{~mm}^{3}$ prism. The details of the cubes are given in the following Tables 4 and 5 .

\section{Results and Discussions}

\section{Elastic Properties}

Ultrasonic pulse-echo measurements were conceded out at various locations along the gradient to attain the local 
Fig. 4 Failure cracks of the cubes

Fig. 5 Method to determine the bond strength of FGM cube
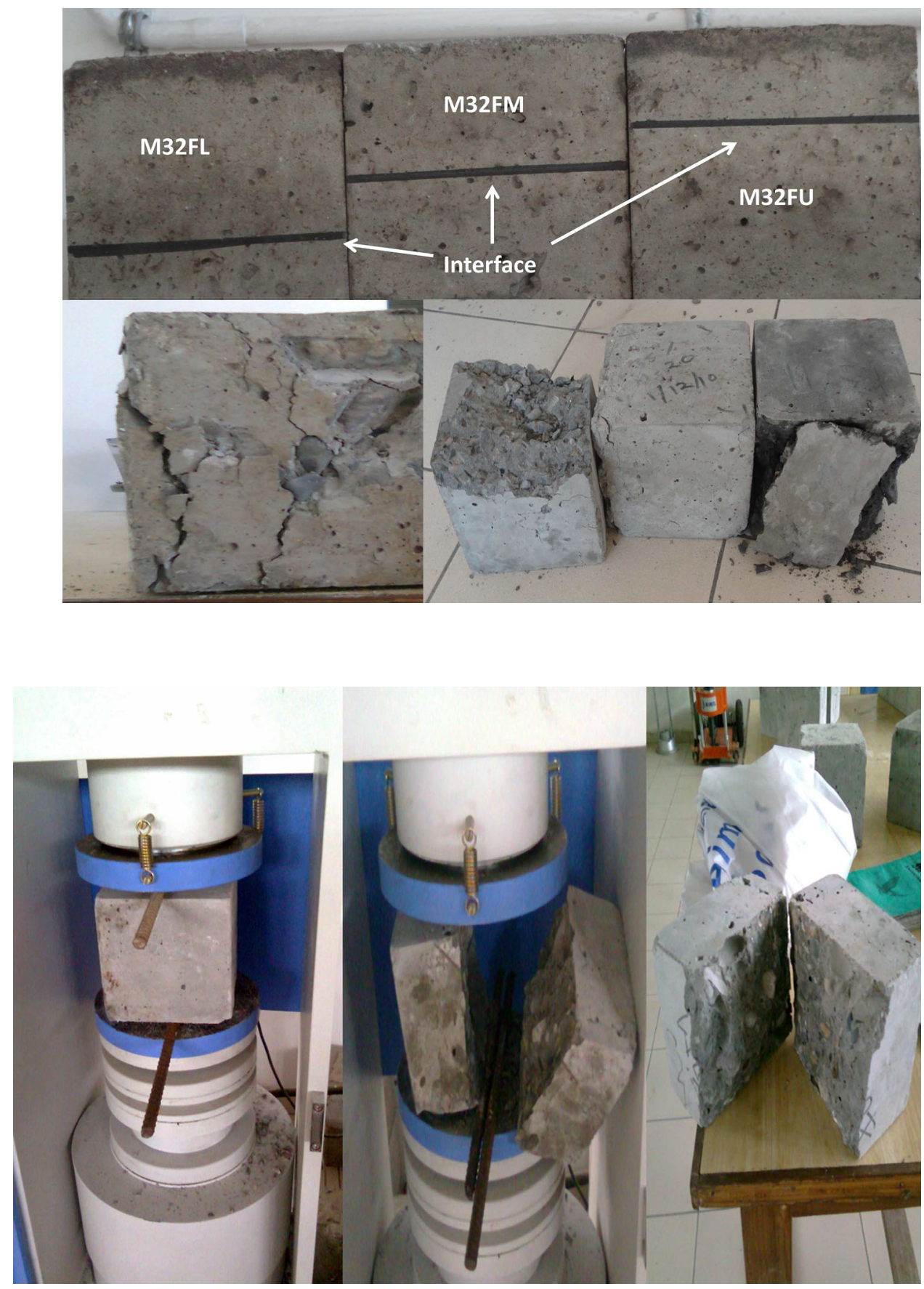

values of longitudinal velocity, $\mathrm{C}_{1}$. " $\mathrm{C}_{1}$ against $\mathrm{E}$ " (where $\mathrm{E}$ is Young's modulus) has been developed by the chart by the researchers [20] for this specific concrete mixture was then used to reclaim the deviation in elastic modulus within the FGM prism. The Fig. 2a-f show the Young's modulus variation of different specimen [as per Tables 4 and 5] with respect to volume fraction $\left(V_{f}\right)$. All castings exhibit an asymmetric sigmoidal behavior in elastic modulus. The elastic modulus increases monotonically with $V_{f}$. Figure 2 also includes the curves demonstrating variation of elastic modulus with respect to volume fraction as projected by the researchers [21] lower bound estimation based on the "rule-of-mixtures". The Halpin-Tsai prediction for the elastic modulus of the composite is,

$E=\frac{E_{N C}\left(E_{F A C}-2 s E_{N C}+2 s V_{f} E_{F A C}-2 s V_{f} E_{N C}\right)}{E_{F A C}-2 s E_{N C}-V_{f} E_{F A C}+V_{f} E_{N C}}$

where $\mathrm{s}=1$ for spherical intrusion, $V_{f}$ is the volume fraction varies as $0,0.25,0.5,0.75$ and $1, E_{N C}$ is the modulus of elasticity of the normal concrete of different 


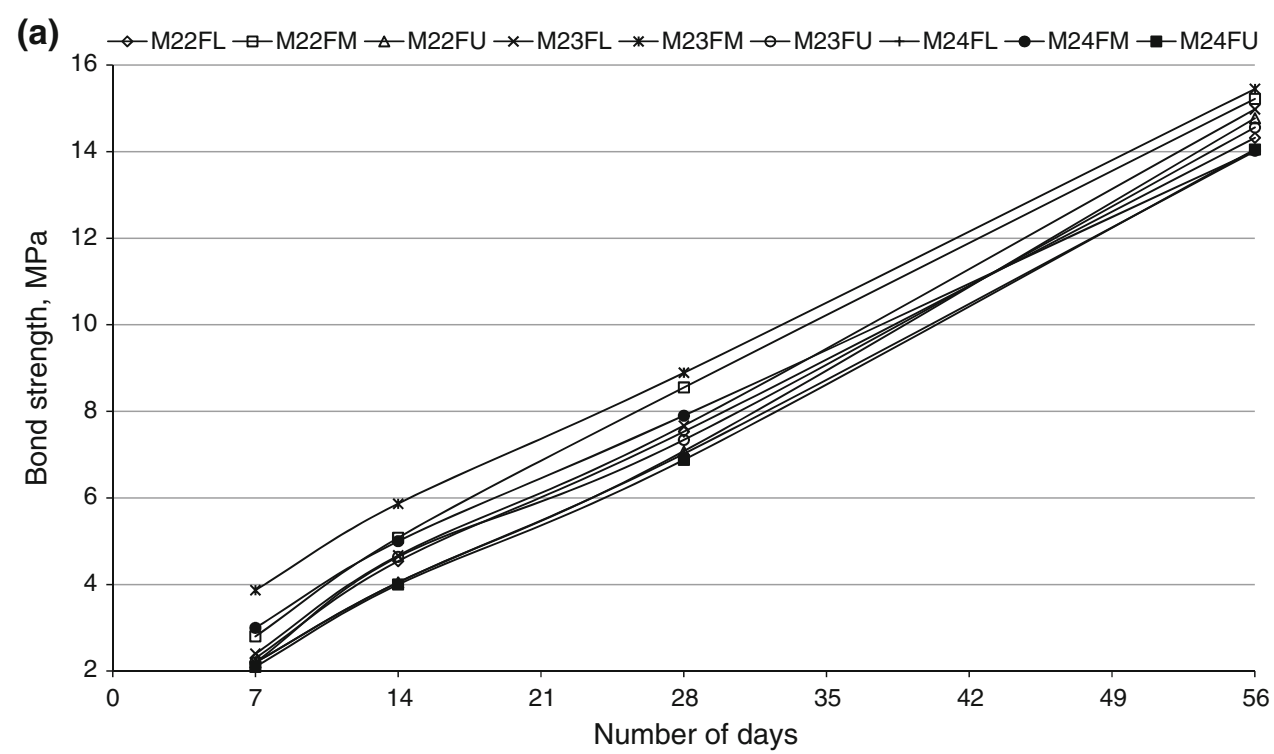

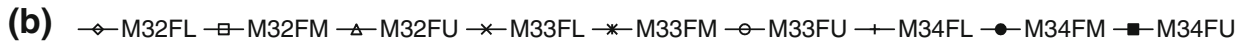

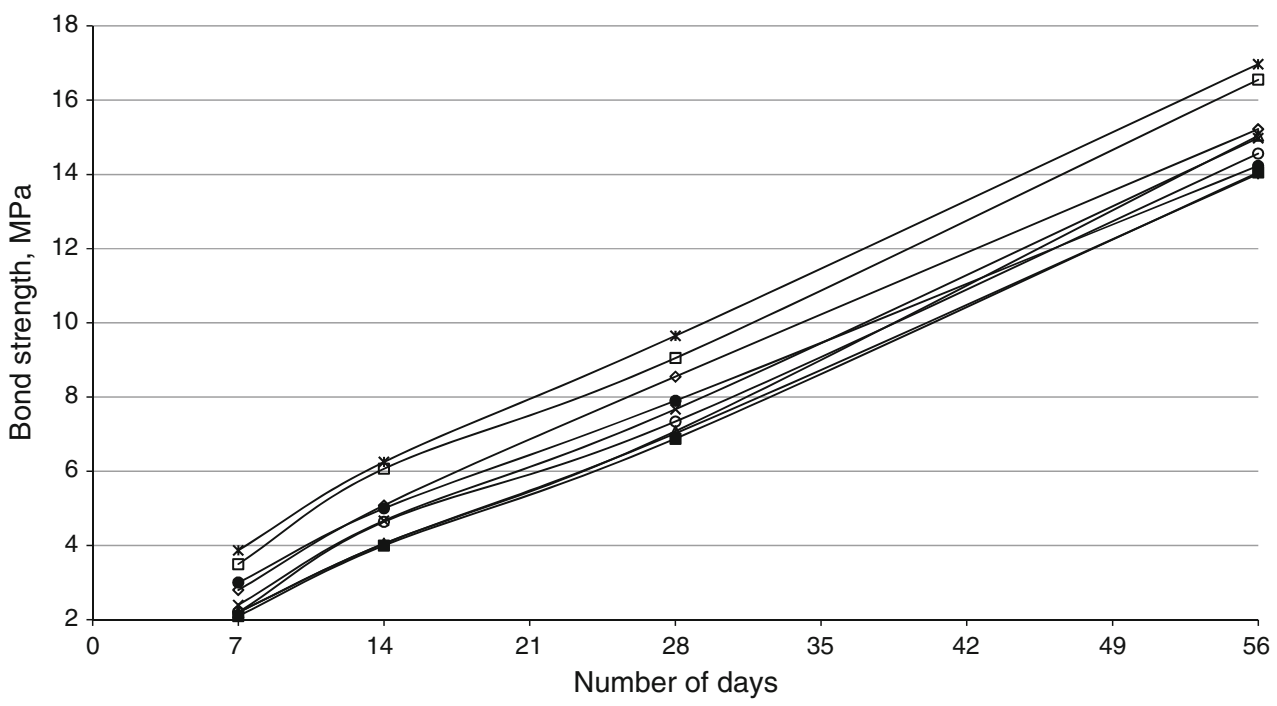

Fig. 6 Comparison of bond strength of M20 and M30 grade of concrete specification as per Table 5. a Bond Strength of FGM cubes of M20 grade concrete cubes as per Table 5. b Bond Strength of FGM cubes of M30 grade concrete cubes as per Table 5

specimen as described in Table 4 and $E_{F A C}$ is the modulus of elasticity of the fly ash concrete specimen as per Table 5. The Halpin-Tsai equation consistently over-predicts the elastic modulus.

\section{Compressive Strength of Cubes}

The compressive strength of cubes of M20 grade and M30 grade of concrete is tested [19] by the variation in interface. It has been shown that M22FM, M23FM, M24FM, M32FM, M33FM and M34FM have more compressive strength as compared to other cubes of M20 and M30 grade as per Table 5. It has been also seem that the cube having interface at the middle has approximately $18 \%$ more compressive strength as compared to normal concrete and 10-12\% more compressive strength as compared to fly ash concrete. The compression of all the cubes of M20 and M30 [Tables 4, 5] has been shown in Fig. 3a-f. The failure cracks of the cubes are also shown in Fig. 4.

\section{Bond Strength of Cubes}

There are no standard methods for determining the bond strength of FGM cubes interface layer. Hence, the common splitting cube test to measure the tensile strength of the concrete was used to obtain a relative approximate value of the bond strength of interface layer. It is shown in Fig. 5. 

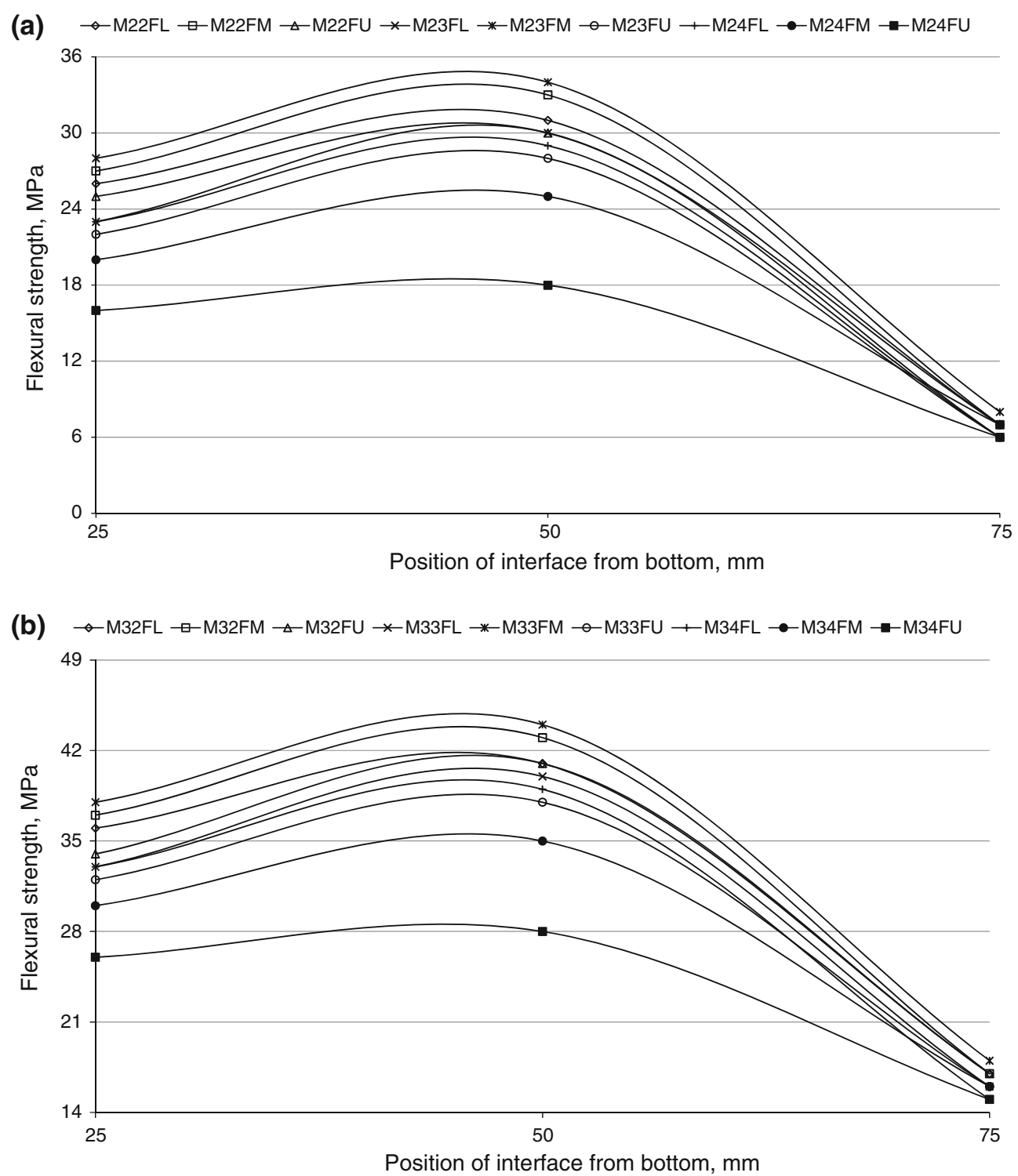

Fig. 7 a Change in flexural strength with position of interface of M20. b Change in flexural strength with position of interface of M30

The bond strength of different types of FGM cubes of M20 and M30 grade of concrete has been tested at interval of 7, 14, 28 and 56 days which is shown in Fig. 6a, b.

\section{Flexural Strength of Prism}

The prism of dimension $600 \times 150 \times 100$ was casted to determine the felxural strength of the concrete and it has been resulted that M23FM has maximum flexural strength and it has been decreases with increase in amount of fly ash in FGM and also decreases with increase in the position of interface from bottom. The variation in flexural strength with respect to position of interface of M20 and M30 grade of concrete is shown in Figs. 7a, b.

\section{Conclusion}

The paper suggest that FGM cubes having inface at the middle that are M22FM, M23FM, M24FM, M32FM, M33FM and M34FM have approximately $18 \%$ more compressive strength as compared to normal concrete and $10-12 \%$ more compressive strength as compared to fly ash concrete. It also concludes that M23FM and M33FM are more durable and having more compressive strength as compared to other. It has been also seem that M24FU and M34FU has same compressive strength as compared to normal concrete but they are more economical and durable due to resistance against corrosion. 
It was observed that the FGC (functionally graded concrete) have outstanding performance. The compressive strength of the outer layer (covering) of the FGC has been found to be over $28.5 \mathrm{MPa}$ for M20 and $36.23 \mathrm{MPa}$ for M30 grade of concrete at $50 \mathrm{~mm}$ depth of flexural beam of dimension $600 \times 150 \times 100 \mathrm{~mm}^{3}$. The crack-resistance of the FGC was found excellent, and there was no macroscopic crack on the surface of the FGCS. There was no water penetration depth under $0.8 \mathrm{MPa}$ pressure on the 28 days FGC. So analyzing and comparing the hardened properties of FGM as compared to normal concrete and high volume fly ash concrete, its adoption is beneficial to concrete structure.

According to ASTM, the bond strength of the concrete should be more than $7 \mathrm{MPa}$ after 28 days in case of FGM. M23FM and M33FM having bond strength more than $8 \mathrm{MPa}$ which shows that these are more durable as compared to other cubes.

The flexural strength of the prism of FGM M23FM and M33FM is more even that of normal concrete and fly ash concrete. It has also been seem that the flexural strength decrease with increase in interface from bottom as concrete could not have sufficient strength to resist the loading. In case of M24FU and M34FU, the flexural strength goes on decreasing by $4 \%$ as compared to normal cement concrete and $23 \%$ as compared to fly ash concrete.

So it has been determined that the FGM concrete having interface at the middle and fly ash concrete formed by replacement of $35 \%$ of cement by fly ash is having better result as compared to others but for concrete having $55 \%$ replacement of cement with fly ash have same compressive strength as that of normal grade of concrete. So, for FGM concrete high volume fly ash concrete can be used at half of the depth.

Acknowledgments The author would like to acknowledge the Concrete Laboratory, University of Petroleum and Energy Studies, Dehradun, India for the successfully completion of the project.

Open Access This article is distributed under the terms of the Creative Commons Attribution License which permits any use, distribution, and reproduction in any medium, provided the original author(s) and the source are credited.

\section{References}

1. E. Muller, C. Drasar, J. Schilz, W.A. Kaysser, Mater. Sci. Eng. A 362, 17-39 (2003)
2. W. Pompe, H. Worch, M. Epple, W. Friess, M. Gelinsky, P. Greil, U. Hempel, D. Scharnweber, K. Schulte, Mater. Sci. Eng. A 362, 40-60 (2003)

3. B.V. Sankar, An elasticity solution for functionally graded beams. Compos. Sci. Technol. 61(5), 689-696 (2001)

4. A. Chakraborty, S. Gopalakrishnan, J.N. Reddy, A new beam finite element for the analysis of functionally graded materials. Int. J. Mech. Sci. 45(3), 519-539 (2003)

5. Z. Zhong, T. Yu, Analytical solution of a cantilever functionally graded beam. Compos. Sci. Technol. 67(3-4), 481-488 (2007)

6. S. Kapuria, M. Bhattacharyya, A.N. Kumar, Bending and free vibration response of layered functionally graded beam: a theoretical model and its experimental validation. Compos. Struct. 318(4-5), 1210-1229 (2008)

7. R. Kadoli, K. Akhtar, N. Ganesan, Static Analysis of functionally graded beams using higher order shear deformation theory. Appl. Math. Model. 32(12), 2509-2525 (2008)

8. M.A. Benatta, I. Mechab, A. Touni, E.A. Adda Bedia, Static analysis of functionally graded short beams including wrapping and shear deformation effects. Comput. Mater. Sci. 44(2), 765-773 (2008)

9. ACI 232.2R-03, Use of fly ash in concrete. ACI Committee 232 (American Concrete Institute, Farmington Hills, 2000)

10. Structural Engineering Research Council. Demonstration of utilizing high volume fly ash based concrete for structural applications. (Chennai, 2005)

11. Maalej, Li, Functionally graded concrete beams. Int. J. Miner. Process. 59(3), 226-247 (1995)

12. T.C. Hansen, S.E. Hedegaard, Properties of fly ash concrete (Technical University of Denmark, Lyngby, 1989)

13. IS 1727:1967. Methods of test for pozzolanic materials (First Revision)—Reaffirmed-1999. Reaffirmed-2004. (Bureau of Indian Standards, New Delhi)

14. ASTM C618-00, Standard specification for coal fly ash and raw or calcined natural pozzolan for use as a mineral admixture in concrete. (Philadelphia, 1999)

15. IS 2386 (Part I), Methods of test for aggregates for concrete-Part I. Particle size and shape. Bureau of Indian Standards. (New Delhi, 1997)

16. IS 2386 (Part III), Methods of test for aggregates for concretePart III. Specific gravity, density, voids, absorption and bulking. Bureau of Indian Standards. (New Delhi, 1997)

17. IS 2386 (Part IV), Methods of test for aggregates for concretePart IV. Mechanical Properties. (Bureau of Indian Standards, New Delhi, 1997)

18. IS 10262:1982, Concrete Mix proportion (First Revision)Reaffirmed 1999. Reaffirmed 2004. (Bureau of Indian Standards, New Delhi)

19. IS: 516-1999. Methods of tests for strength of concrete. (Bureau of Indian Standards, New Delhi)

20. R.J. Butcher, C.E. Rousseau, H.V. Tippur, Acta Mater. 47(1), 259 (1999)

21. C.E. Rousseau, H.V. Tippur, Compositionally graded materials with cracks normal to the elastic gradient. 2000. Acta Mater. 48, 4021-4033 (2000) 